\title{
Oncology Nurse
}

National Cancer Institute

\section{Source}

National Cancer Institute. Oncology Nurse. NCI Thesaurus. Code C18065.

A nurse who specializes in treating and caring for people who have cancer. 